On some Unapparent Contradictions at the Foundations of Knowledge.

An argument parallel to that by which Mr. Tolver Preston proposes to prove that Space is nothing will prove with equal cogency that Time is nothing. But if Space is nothing and Tirre is nothing, then he has the choice of two alternatives, neither of which will he find particularly acceptable. If Space and Time are both nothings, they are identical. If Space and Time are not identical, then they are two nothings which differ. What is the difference between two nothings?

I would suggest that $\mathrm{Mr}$. Preston should read $\mathrm{Mr}$. Herbert Spencer's views on "The Relativity of Knowledge," contained in Chapter IV. of "First Principles." On his carefully thinking this out, and understanding it, I am willing to hope that the title I have adopted for this letter may appear to him appropriate to the subject-matter which he has brought under the consideration of your readers.

Churchfield, Edgbaston.

\section{Extraordinary Fog in January 1888, at Shirenewton Hall, Chepstow.}

THE recent fog has been so remarkable that it seems desirable to record its principal features. From the 7 th to the I th the air was completely saturated $w$ ith moisture. The most notable feature was that of cold air passing over a warm ground, for from the 11 th to the 15 th the greatest cold on the grass did not descend to that read at 4 feet. Such a condition of the air as this has not been noticed since I commenced observations in 1838 .

The following readings of the thermometers will illustrate this :--

\begin{tabular}{|c|c|c|c|c|c|}
\hline & & $\begin{array}{l}\text { p. }{ }_{4} \mathrm{ft} \\
\text { a.m. }\end{array}$ & & $\begin{array}{l}\text { det and } \\
\text { dry. }\end{array}$ & \\
\hline Jan. & $\ldots$ & & $\ldots$ & $\circ$ & \\
\hline & $\ldots$ & & $\cdots$ & 0.0 & \\
\hline & $\ldots$ & & $\ldots$ & 0.0 & .. \\
\hline & $\ldots$ & & $\ldots$ & 0.0 & .. \\
\hline & $\ldots$ & & $\ldots$ & $0^{\circ}$ & \\
\hline & $\ldots$ & & $\ldots$ & 0.0 & \\
\hline & $\ldots$ & $3 \cdot 3$ & $\ldots$ & & \\
\hline & $\ldots$ & & $\ldots$ & 00 & \\
\hline & $\ldots$ & & $\ldots$ & I.O & \\
\hline & $\ldots$ & & $\ldots$ & & \\
\hline & & & $\cdots$ & $I$ & \\
\hline & & & & 0.0 & \\
\hline & & $31 \cdot 7$ & $\ldots$ & 0.4 & \\
\hline
\end{tabular}

\begin{tabular}{ccccr}
$\begin{array}{c}\text { Min. } \\
4 \mathrm{ft.}\end{array}$ & \multicolumn{3}{c}{$\begin{array}{c}\text { Min. } \\
\text { grass. }\end{array}$} & Diff. \\
$40^{\circ} \circ$ & $\ldots$ & $34 \cdot 5$ & $\ldots$ & $-5 \cdot 5$ \\
$42 \cdot \mathrm{I}$ & $\ldots$ & $37 \cdot 2$ & $\ldots$ & $-4 \cdot 9$ \\
$37 \cdot 0$ & $\ldots$ & $30 \cdot 3$ & $\ldots$ & $-6 \cdot 7$ \\
$32 \cdot 8$ & $\ldots$ & $28 \cdot 1$ & $\ldots$ & $-4 \cdot 7$ \\
$33 \cdot 3$ & $\ldots$ & $37 \cdot 3$ & $\ldots$ & $+4 \cdot 0$ \\
$29 \cdot 3$ & $\ldots$ & $30 \cdot 5$ & $\ldots$ & $+1 \cdot 2$ \\
$26 \cdot 7$ & $\ldots$ & $28 \cdot 3$ & $\ldots$ & $+1 \cdot 6$ \\
$25 \cdot 0$ & $\ldots$ & $29 \cdot 5$ & $\ldots$ & $+4 \cdot 5$ \\
$28 \cdot 0$ & $\ldots$ & $30 \cdot 0$ &.. & $+2 \cdot 0$ \\
$27 \cdot 0$ & $\ldots$ & $27 \cdot 0$ & $\ldots$ & $0 \cdot 0$ \\
$29 \cdot 7$ & $\ldots$ & $29 \cdot 7$ & $\ldots$ & $0 \cdot 0$ \\
$27 \cdot 0$ &.. & $27 \cdot 0$ & $\ldots$ & $0 \cdot 0$ \\
$26 \cdot 4$ & $\ldots$ & $24 \cdot 8$ & $\ldots$ & $-1 \cdot 6$ \\
& & & &
\end{tabular}

Throughout the I 2 th after $9 \mathrm{a} . \mathrm{m}$. the temperature on the grass was above $32^{\circ}$, whilst it was a frost from the height of $I$ foot upwards; at IO a.m. the temperature on grass was $32^{2} \cdot 8$, at 4 feet $29^{\circ} \cdot 8$, and at io feet $28^{\circ} \cdot 6$.

The fog lasted from the evening of the 6 th till $3 \mathrm{p} . \mathrm{m}$. of the I 4 th. On the 7 th the clouds moved rapidly in $W$. current, and on the 8 th they moved rapidly in S. W. current ; on the 9 th nearly calm and cloudless overhead; from the Ioth to 14 th overcast (except from II a.m. on the I 2 th till I $2.40 \mathrm{p.m}$.). The chief direction of the wind was: 8 ih S.S.W., 9 th S.S.E., Ioth W.S.W., IIth and 12 th calm, and from 13 th to 18 th between N. and N.E., and on the I 1 th E.S.E.

The fog was wet and yielded much moisture, viz. :-

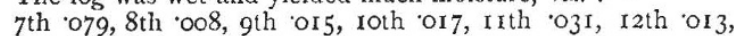
I3th 020 , I4th '020, I5th 023 .

The b.rometer was very high, and almost stationary, reaching a maximum on the 9 th at 10 h. $30 \mathrm{~m}$. a.m., viz. $30^{\circ} 75$ inches corrected and reduced to the sea-level.

On the I Ith the fog cloud moved in a south current till $3 \mathrm{p} . \mathrm{m}$., when it became north, and continued so throughout the I 2 th. On this day on the side facing the fog current every leaf and twig had a horizontai deposit of ice, increasing in length from half an inch at 4 feet above the ground to fully an inch at ro feet; the outside edge of this ice being as thin as the fine edge of a knife ; and the whole upper surface of all laurel and other large leaves that were horizontal had a coating of ice, so thin (although it could be detached without breaking) as almost to resemble gold. leaf, on which were transparent impressions of very irregularity, however minute. On the side of trees opposite to this current, instead of rime there were nearly pear-shaped transparent drops of frozen water, of various sizes, mostly as large as one-eighth of an inch in diameter; they were situated not quite at the point of every leaf; no leaf was without a frozen drop, and this had an extraordinary appearance, more especially amongst the crowded leaves of such plants as Pinus insignis, Abies Webbiana, \&c. On the opposite side of these fir-trees the appearance was equally singular, as each leaf looked like a knife-blade of onesixth of an inch in width, with a square apex. The groundtemperature being above $32^{\circ}$, the vivid green of the grass was a great contrast to the ice on the trees.

E. J. Lowe.

\section{"The Art of Computation for the Purposes of Science."}

IN a paper with the above title, in NATURE, vol. xxxvii. p. 237, Mr. Sydney Lupton refers to some of our work as affording good example of "the natural tendency of the human mind . . . . to exalt the accuracy of one's own experiments."

The experimental work referred to was a determination by the dynamical method of the vapour pressures of liquid benzene. A curve was drawn to represent these relations; three points were chosen, and the constants for the formula $\log p=a+b a t$ were calculated. Mr. Lupton finds fault with the number of decimal places given for these constants, and makes three statements which are intended to put the experimental work in as unfavourable a light as possible so as to heighten the contrast with the extreme accuracy of the calculations. Mr. Lupton says : "Nine places of decimals are given with apparent confidence, when (i) only three of the whole number of experiments were made even in duplicate." We do not quite understand this statement, for on reference to the original paper (Phil. Mag., Jan. I887) it will be seen that the last six experiments in Series I. overlap the first six in Series II, while the last seven of Series II. are within the same limits of temperature as the first four of Series III. The second statement is that "the last pressure, 755, was obtained not by experiment at all, but by extrapolation from a freehand curve, the highest experiment being $79^{\circ} .6$ and $743^{\prime} \mathrm{mm}$." We would point out that the experiment referred to is not the highes', for on the preceding page in our paper the bo ling point $79^{\circ} \cdot 9$ at $753^{\circ} 4 \mathrm{~mm}$. is given. Again, the curve was not drawn by freehand, but by means of engineers' curves, which give very much more accurate results. It is quite true that the last pressure was obtained by extrapolation, but an extrapolation of $0^{\circ} \cdot 1$, or even of $0^{\circ} \cdot 4$ does not seem very excessive with a range of $80^{\circ}$. Mr. Lupton states, thirdly, that "a difference of $\frac{1}{9}^{\circ}$ at low temperatures produced no change in pressure which was appreciable by the apparatus used." But, as a matter of fact, at $0^{\circ}$ a difference of $O^{\circ} \cdot I$ corresponds to a difference of pressure of $0.15 \mathrm{~mm}$., which is quite appreciable on our gauge. Perhaps, however, Mr. Lupton refers to the experiments at $36.15 \mathrm{~mm}$, in which at the same pressure two different thermometers registered temperatures which differed by $i^{\circ}$.

Mr. Lupton lastly gives much simpler constants, calculated from our data, and compares the pressure at $60^{\circ}$, calculated from them and from our constants, with the pressure given by Regnault. It happens that the number obtained with the simpler constants exhibits greater concordance with Regnault's value. Now while we would agree with Mr. Lupton in classing Regnauit (as far at least as some of his work is concerned) with the select few who are entitled to an extra number of decimal places, yet we would point out that Regnault did not always succeed in obtaining perfectly pure substances to work with, and some of his results are rendered almost valueless on that account. In this case, for instance, the melting-point of Regnault's sample of benzene was $4^{\circ} \cdot 44$, whereas after the most careful purification we find that it melts at $5^{\circ} 5^{8}$, and the value obtained by Fischer (Wiedemann's Annalen, xxviii. 400) is almost exactly the same as ours. Again, Regnault failed to observe the existence of a difference in the vapour pressure of solid and liquid benzen: (and other substances) at the same temperature, while this difference has been measured by Fischer by the statical and by ourselves by the dynamical method.

We are quite willing to admit that our decimal points are carried further than is recessary for the calculation of the vapour pressures, but we have frequently had occasion to calculate the values of $\frac{d p}{d t}$ for various substances, and we have found that in order to obtain regular values a large number of decimal places are required; if a smaller number are employed the 